\title{
Toz metalürjisi yöntemi ile üretilmiş magnezyum matrisli kompozitlerin korozyon duyarlılıkları
}

\author{
Fevzi KELEN ${ }^{1 *}$, Tarık AYDOĞMUŞ², Mehmet GAVGALI ${ }^{3}$, Burak DİKİCI ${ }^{4}$ \\ ${ }^{1}$ Van Yüzüncü Yıl Üniversitesi, Motorlu Araçlar ve Ulaştırma Teknolojileri Bölümü, Van \\ ${ }^{2}$ Van Yüzüncü Yll Üniversitesi, Makine Mühendisliği Bölümü, Van \\ ${ }^{3}$ Atatürk Üniversitesi, Makine Mühendisliği Bölümü, Erzurum \\ ${ }^{4}$ Atatürk Üniversitesi, Metalürji ve Malzeme Mühendisliği Bölümü, Erzurum \\ (ORCID: 0000-0003-3900-4503) (ORCID: 0000-00020928-5095) \\ (ORCID: 0000-0002-1581-2605) (ORCID: 0000-0002-7249-923X)
}

\begin{abstract}
$\ddot{O} \mathbf{z}$
Bu çalışmada, hacimce \%5-25 oranında TiNi mikro partikül içeren magnezyum matrisli kompozitlerin korozyon davranışları \%3,5 $\mathrm{NaCl}$ çözeltisi içerisinde potansiyodinamik polarizasyon (PDS) testleri ile belirlenmiştir. Korozyon potansiyeli $\left(\mathrm{E}_{\text {cor }}\right)$ ve korozyon akım yoğunluğu $\left(i_{\text {corr }}\right)$ değerleri Tafel ekstrapolasyonu yöntemi ile saptanmışı̧ır. İçyapıdaki değişimler ve elektrokimyasal sonuçlar birbirini desteklemektedir. Kompozit malzemelerde artan takviye oranı ile birlikte hem korozyon potansiyeli hem de korozyon akım yoğunluğu değerlerinin artığı gözlenmiştir. Korozyon testlerinden sonra gerçekleştirilen morfolojik incelemelerde yüzeyde çukurcukların yanı sıra kurtçuklar da tespit edilmiştir.
\end{abstract}

Anahtar kelimeler: Magnezyum, TiNi Alaşımlar, Kompozit Malzemeler, Toz Metalürjisi, Korozyon.

\section{Corrosion resistance of magnesium matrix composites produced by powder metallurgy method}

\begin{abstract}
In this study, the corrosion behavior of magnesium matrix composites containing TiNi micro-particles of 5-25\% by volume was investigated. Corrosion resistance was determined by potentiodynamic polarization (PDS) tests in $3,5 \% \mathrm{NaCl}$ solution. The corrosion potential and corrosion current density values of the composites were determined by Tafel extrapolation method. Electrochemical evaluations were supported by metallographic investigations before and after corrosion. The results obtained from experimental studies showed that both the corrosion potential and the corrosion current density values increased with the increasing amount of reinforcement. In the morphological investigations made after the corrosion, pitting and filiform corrosion types were observed in all the composite samples.
\end{abstract}

Keywords: Magnesium, TiNi Alloys, Composite Materials, Powder Metallurgy, Corrosion.

\section{Giriş}

Düşük yoğunluğu ile tüm yapısal malzemeler arasında en hafif olan magnezyum, alüminyumdan \%36, demirden ise $\% 78$ daha hafiftir. Magnezyum ve alaşımları düşük yoğunluklarının yanı sıra yüksek spesifik mukavemet, kolay geri kazanım, yüksek ısıl iletkenlik ve mükemmel sönümleme kapasitesi gibi üstün özelliklere sahiptir [1-4]. Bu tür malzemeler; cep telefonu, kamera ve taşınabilir bilgisayar kasalarının imalatı, çeşitli ev eşyalarının yapımı, biyomalzeme uygulamaları ve metalürjik prosesler gibi farklı alanlarda kullanım alanı bulmakta ve düşük yoğunluğun kritik bir parametre olduğu otomotiv endüstrisinde kullanımları giderek artmaktadır [5-6]. Nitekim magnezyum ve alaşımlarının otomobillerde birçok uygulaması bulunmasına karşın asıl kullanım alanlarının taşıt ağırlığının önemli

\footnotetext{
*Sorumlu yazar: fkelen@yyu.edu.tr

Geliş Tarihi: 25.12.2018, Kabul Tarihi: 07.05.2019
} 
bir kısmını oluşturan güç aktarma organları bileşenleri olacağı düşünülmektedir. Ancak magnezyumun zayıf korozyon direnci bu uygulamalardaki kullanımlarını sınırlamaktadır [7,8]. Magnezyumun düşük korozyon direncinin nedeni, yüksek elektronegatif potansiyel ve yüzeyde oluşan koruyucu oksit film tabakasının kararsız bir yapıya sahip olmasıdır. Yüzeyde meydana gelen oksit tabaka birçok sulu veya nemli ortamlarda çözünürken, yüksek elektronegatif potansiyelde oksijensiz ortamlarda dahi korozyonun devam etmesine sebep olur [9-10]. Bu nedenle gerek magnezyum ve alaşımlarının gerekse de magnezyum esaslı kompozitlerin korozyon dayanımlarının iyileştirilmesi büyük önem arz etmektedir [11,12]. Literatürde magnezyum matrisli kompozitlerin düşük mekanik özellikleri saf bakır, nikel, titanyum, Ti6A14V ve TiNi alaşımları ile iyileştirilmeye çalışılmış olmasına karşın bu takviye materyallerinin korozyon özellikleri üzerine etkisi hakkında bilgi oldukça sınırlıdır [13-16]. Ayrıca TiNi alaşımının saf magnezyumun korozyon dayanımı üzerindeki etkisinin araştırılması literatürde bir ilk olma özelliğine sahiptir. Dolayısıyla bu çalışmanın amacı, korozyon direnci 300 serisi paslanmaz çelikler ile benzer olan [17] TiNi mikro partiküller ile takviye edilmiş magnezyum matrisli kompozitlerin korozyon özelliklerinin ortaya çıkarılmasıdır.

\section{Materyal ve Metot}

Mevcut çalışmada, hacimce $\% 5, \% 10, \% 15, \% 20$ ve $\% 25$ oranlarında TiNi mikro partiküller ile takviye edilmiş magnezyum matrisli kompozitler toz metalürjisi metotlarından biri olan tek eksenli sicak presleme tekniği ile üretilmiştir. Deneysel çalışmalarda kullanılan, ticari saflıktaki magnezyum tozlar, Magnezyum ve Metal Tozları End. ve Tic. A.Ş. (Türkiye), TiNi mikro partiküller ise AP\&CAdvanced Powders and Coatings Inc. (Kanada) firmasından tedarik edilmiştir. Ticari saflıktaki magnezyum partiküller ağırlıkça \%99 magnezyumdan oluşurken, TiNi mikro partiküller atomik olarak \%49,2 Ti ve $\% 50,8$ Ni'den meydana gelmektedir. Magnezyum partiküllerin boyutu 100-300 $\mu \mathrm{m}$ arasında değişmekte iken, takviye materyalinin partikül boyutu ise ortalama $45 \mu \mathrm{m}$ 'dur. Matris ve takviye partiküller yukarıda belirtilen oranlarda seramik bir kap içerisinde çelikten üretilmiş bir spatula vasıtasıyla karıştırılmış, optimum karıştırma süresi 10 dakika olarak belirlenmiştir. Karıştırma işleminden sonra matris ve takviye partiküller iç çap $10 \mathrm{~mm}$ olan silindirik grafit kalıplarda, $420^{\circ} \mathrm{C}$ 'de, 1 saat süre ile 50 MPa basınç altında, argon gazı atmosferinde sıcak preslenmiştir. Numuneler; $40 \mathrm{~mm}$ çapında ve $10 \mathrm{~mm}$ kalınlığındaki kompozit malzemelerden tel erozyon yöntemiyle $5 \times 5 \times 10 \mathrm{~mm}^{3}$ boyutlarında kesilerek elde edilmiştir $[18,19]$. Korozif özellikler potansiyodinamik polarizasyon (PDS) deneyleri ile tespit edilmiştir. Korozyon parametrelerinin hesaplanmasında Tafel ekstrapolasyonu yöntemi kullanılmıştır. Korozyon öncesi ve sonrası numunelerin yüzey morfolojileri taramalı elektron mikroskobu (SEM) yardımı ile belirlenmiştir.

\subsection{Elektrokimyasal deney}

Elektrokimyasal testler için numuneler tel erozyon yöntemiyle $10 \mathrm{~mm}$ kalınlığında kesilmiş, daha sonra numune yüzeyine $1,5 \mathrm{~mm}$ çapında, 2,5 $\mathrm{mm}$ derinliğinde delikler açılmıştır. Elektrik iletkenliğinin sağlanabilmesi amacıyla bu deliklere bakır teller sıkı geçme olarak monte edilmiş ve polipropilen borular içerisinde epoksiye alınmıştır. Kompozit numunelerin soğuk kalıplama işlemleri $\mathrm{NaCl}$ çözeltisine yapılan daldırma yöntemiyle kontrol edilmiştir. Dolayısıyla epoksinin numune yüzeyine tam olarak temas edip etmediği belirlenmiştir. Sonrasında korozyona uğratılacak yüzeyler zımparalama ve parlatma işlemlerine tabi tutulmuş, potansiyodinamik polarizasyon (PDS) testleri öncesinde tüm numunelere etil alkol içerisinde 5 dakika süreyle ultrasonik temizleme yapılmıştır. Korozyon deneyleri ASTM standartlarına göre GAMRY (USA) firmas1 tarafindan üretilen PCI14/750 potansiyostat/galvanostat test cihazı kullanılarak \%3,5 $\mathrm{NaCl}$ çözeltisi içerisinde gerçekleştirilmiştir. Elektrokimyasal test hücresi olarak $400 \mathrm{ml}$ hacminde beher kap kullanılmıştır. Kompozit numunelerin korozyon davranışları üç elektrot tekniği vasıtasıyla belirlenmiş, referans elektrot (RE) olarak doygun gümüş/gümüş klorür $(\mathrm{Ag} / \mathrm{AgCl})$, karşıt elektrot $(\mathrm{CE})$ olarak platin $(\mathrm{Pt})$ ve çalışma elektrodu $(\mathrm{WE})$ olarak da yüzey alanı $0,25 \mathrm{~cm}^{2}$ olan numuneler kullanılmıştır. Çalışma elektrodu ile referans elektrot arasındaki potansiyel farkının ölçülmesi sırasında akımın referans elektrot yerine, karşıt elektrottan geçmesi sağlanarak referans elektrot potansiyelinin, devreden geçen akım tarafindan etkilenmesi önlenmiştir. PDS testleri öncesi elektrotlarla elektrolitin denge potansiyeline ulaşması için açık devre potansiyelleri izlenmiştir. PDS eğrileri -2 V'dan 1 V'a kadar, katodikten, anodik yöne doğru $0.5 \mathrm{mV} / \mathrm{sn}$ tarama hızında 
polarize edilmiştir. Deneyler en az üç kez tekrar edilerek eğrilerin yenilenebilirlik düzeyleri belirlenmiştir.

\section{Bulgular ve Tartışma}

Matris malzemesi olarak kullanılan saf magnezyum ve TiNi ile güçlendirilmiş magnezyum matrisli kompozitlerin korozyon öncesi ve sonrası yüzey morfolojilerine ait SEM görüntüleri sırasıyla Şekil 1ah'de görülmektedir. Şekillerde yukarıdan aşağıya doğru takviye oranı \% 0'dan başlayarak \%25'e kadar artmaktadır. Korozyon öncesi saf magnezyum numunenin içyapısında sadece $\alpha$ fazı görülmektedir (Şekil 1a). TiNi ile güçlendirme sonrasında içyapı $\alpha$ fazın yanı sıra B2 (takviye elemanı TiNi'den gelen) fazını da içermektedir (Şekil 1c, e ve g). Tüm güçlendirici takviye oranları için B2 fazının matris faz içerisinde homojen olarak dağıldığı ve matris ile B2 fazı arasında gözeneksiz bir ara yüzey oluştuğu gözlenmiştir. Gözeneklerin takviye tozları arasında meydana geldiği ve artan takviye miktarıyla arttı̆̆ belirlenmiştir. \%5 takviye içeriğinde ortalama gözeneklik \%2,13 iken, bu değer \%25 takviye oranında $\% 5,13$ 'e kadar yükselmiştir. TiNi fazının maksimum takviye içeriğinde (\%25 TiNi) üç boyutlu bir ağ yapısına dönüştüğü ve bu yapının büyük çoğunluğunun birbiri ile bağlantılı olduğu tespit edilmiştir (Şekil 1g). Korozyon sonrası yapılan morfolojik incelemelerde ise numune yüzeyinde çok miktarda çukurcuk oluşumuna rastlanılmıştır (Şekil 1f). Literatürde magnezyum ve alaşımlarının klorlü ortamlarda çukurcuk korozyonu şeklinde hasara uğradığı rapor edilmektedir [20-22]. Kompozitlerde çukurcuk korozyonunun yanı sıra kurtçuk (filiform) korozyonu da gözlenmiştir (Şekil 1h).

Geliştirilen kompozitlerin otomobil silindir bloğu, silindir kapağ kutusu gibi güç aktarma organı malzemesi olarak kullanılabileceği öngörülmektedir. Bu parçaların servis sırasında klorlu çözeltilere maruz kalmaları nedeniyle korozyon testleri $\% 3,5 \mathrm{NaCl}$ çözeltisinde gerçekleştirilmiştir. \%3,5 NaCl çözeltisi içerisinde saf magnezyum ve $\% 5, \% 10, \% 15, \% 20$ ve $\% 25 \mathrm{TiNi}$ ile takviye edilmiş magnezyum matrisli kompozitlerin potansiyodinamik polarizasyon eğrileri Şekil 2 'de ve bu eğrilerden elde edilen korozyon potansiyeli $\left(E_{\text {corr }}\right)$ ve korozyon akım yoğunluğu $\left(i_{\text {corr }}\right)$ değerleri Tablo 1'de verilmiştir. TiNi oranındaki artı̧̧ ile korozyon potansiyeli de pozitif yönde artmaktadır (Şekil 2). Fakat aynı grafikte takviye fazı TiNi oranındaki artış ile korozyon akım yoğunluğunun da arttığı görülmektedir. Her ne kadar takviye elemanı oranındaki artış ile mekanik özelliklerde artış sağlansa da [15-16, 23]; TiNi'in varlığı hem korozyon akım yoğunluğunun hem de korozyon potansiyelinin artmasina neden olmaktadır. Dolayısıyla her oranda TiNi ilavesi matris malzemesinin korozyon direncini azaltmış, korozyon hızını da artırmıştır (Şekil 2 ve Tablo 1). Kullanılan çözeltinin yüksek oranda $\mathrm{NaCl}$ içermesi nedeniyle pasifleşme eğilimine rastlanılmamıştır. Artan TiNi miktarı ile korozyon akımındaki artışın, TiNi fazının matris fazına göre daha soy olması ve katot görevini üstlenmesinden kaynaklandığı düşünülmektedir. Dolayısıyla içyapıdaki TiNi oranı arttıkça katot yüzey alanı büyümekte ve korozyon akım yoğunluğu artmaktadır (büyük katot yüzey alanı etkisi). Magnezyum yüzeyinde oluşan oksit tabaka birçok sulu ortamda çözünebilir özelliğe sahiptir [910]. $\mathrm{Bu}$ nedenle magnezyum oksit genelde koruyucu değildir. Oluşan magnezyum oksitler yüzeye yapışmaz, yüzeyi terk eder. Ayrıca bölgesel olarak yüzeyde bulunan TiNi fazı, yüzeyde oluşan oksit tabakanın sürekliliğinin bozulmasına ve meydana gelen doku bozukluğuna, pasif tabakada kırılma ve ayrışmaya yol açan bası gerilmelerine de neden olabilir [24]. Korozyon testleri boyunca klor iyonları hasara uğramış pasif yapı içerisine sızarak asidik özellikte olan magnezyum tuzlarını oluşturup kompozitlerin çözünmesini hızlandırmış olabilir [25].

TiNi takviye fazının matrise göre daha soy olması nedeni ile korozyona uğramadığı, korozyonun matris ile takviye ara yüzeyinde ilerlediği, matris fazda meydana gelen hasar sonucu etrafi boşalan takviye elamanlarının yapı içerisinden ayrıldığı gözlenmiştir (Şekil 1f). Tane sınırlarında korozyonun büyük hızla ilerlediği ve TiNi fazının yapıyı terk ettiği Şekil 1 f'de görülmektedir. Korozyon testleri sonrasında yüzeyde çukurcuk ve kurtçuklar (Şekil 1h) oluşmuştur. Yüzeyde çukurların oluşması korozyon türünün çukurcuk korozyonu olduğuna işaret etmektedir. Ayrıca mikro yapıdaki mevcut poroziteler yüzey morfolojisinde süreksizliklere sebep olmakta ve koruyucu oksit tabakayı zayıflatarak korozyon hizının artmasına neden olmaktadır. Klor $\left(\mathrm{CI}^{-}\right)$iyonu konsantrasyonunun porozitelerde artması durumunda, yüzey aktivitelerinin arttığı ve pasif film tabakasının zayıfladığı spesifik noktalar haline gelerek korozyon dayanımının düşmesine neden olduğundan [26] çukurcuk içlerinde korozyon hızı daha etkin hale gelmektedir. 


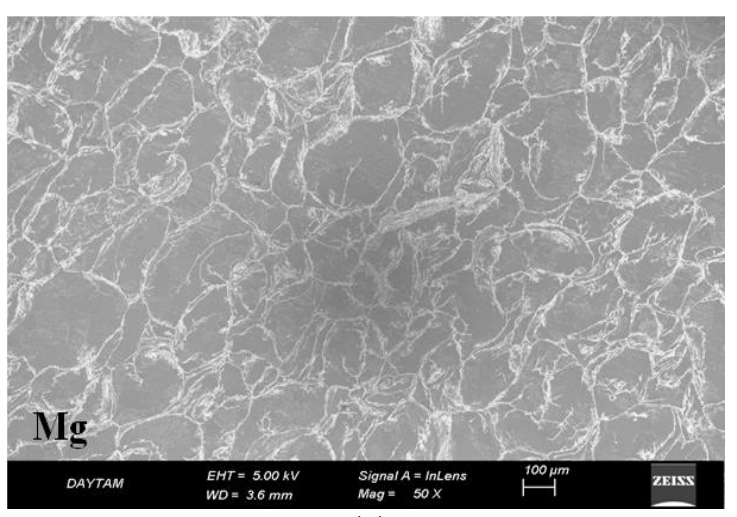

(a)

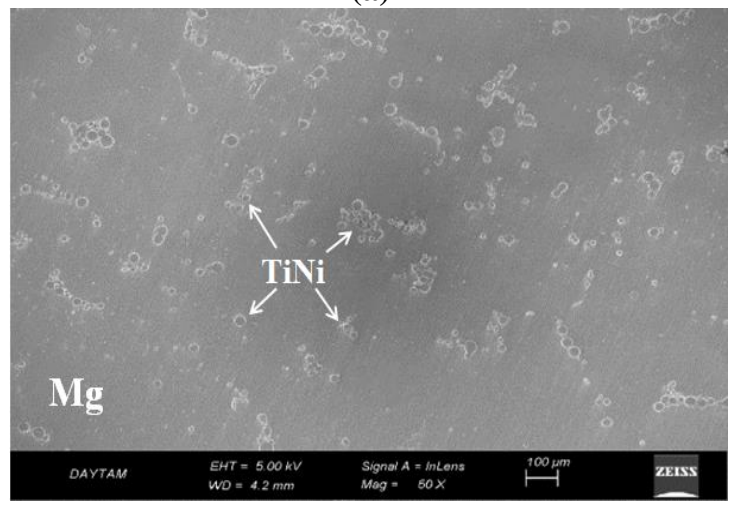

(c)

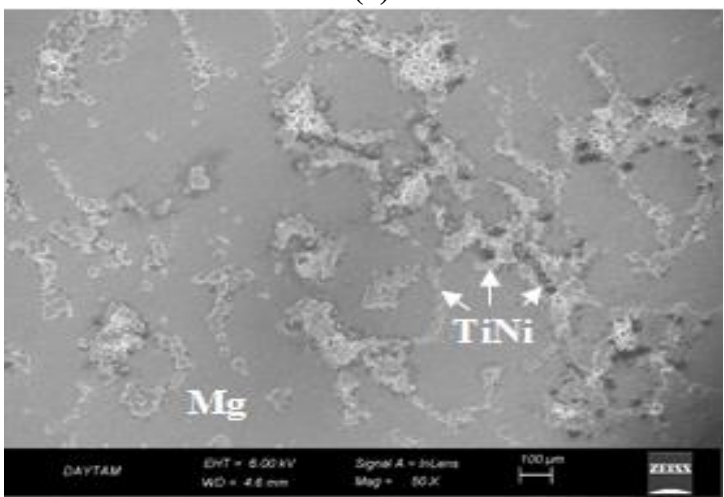

(e)

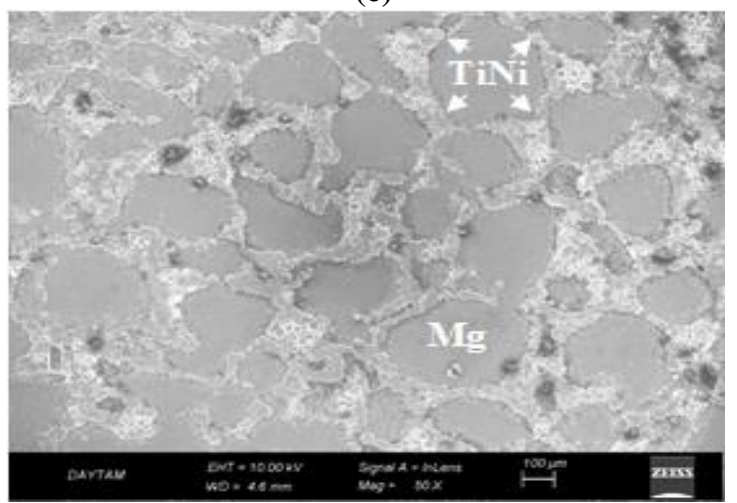

(g)

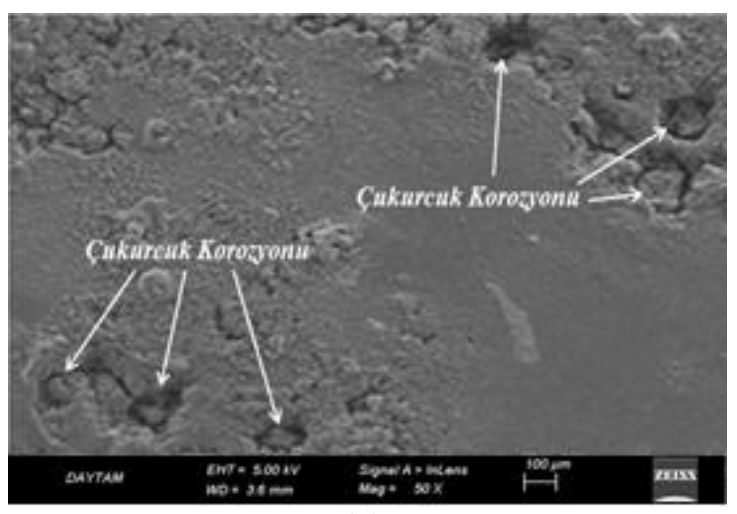

(b)

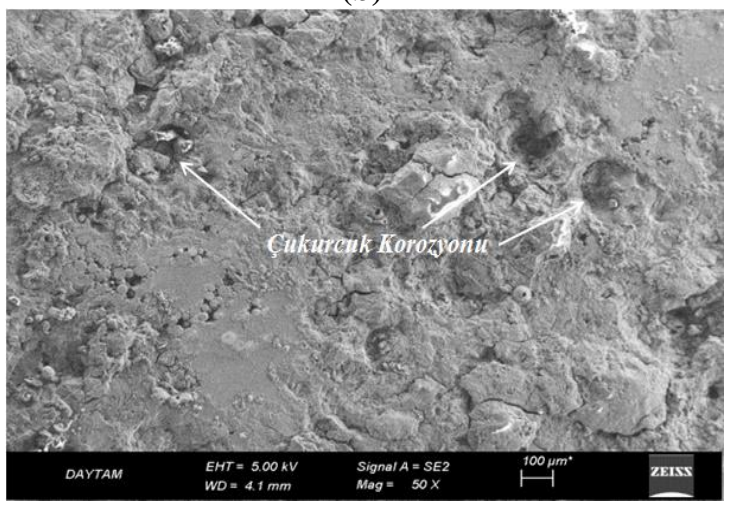

(d)

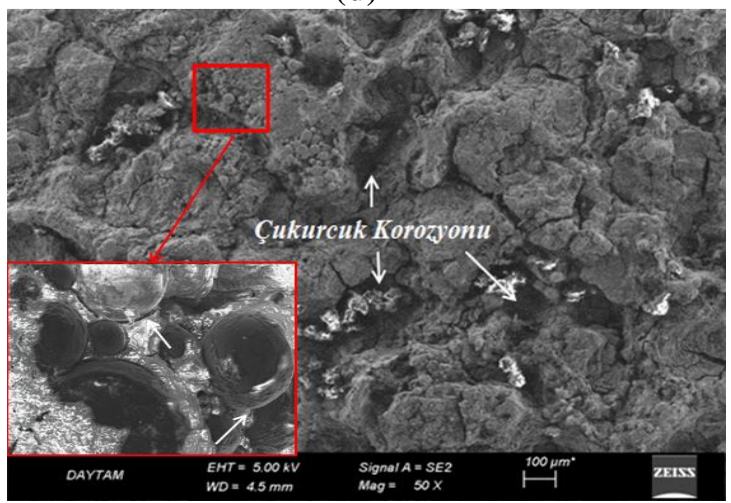

(f)

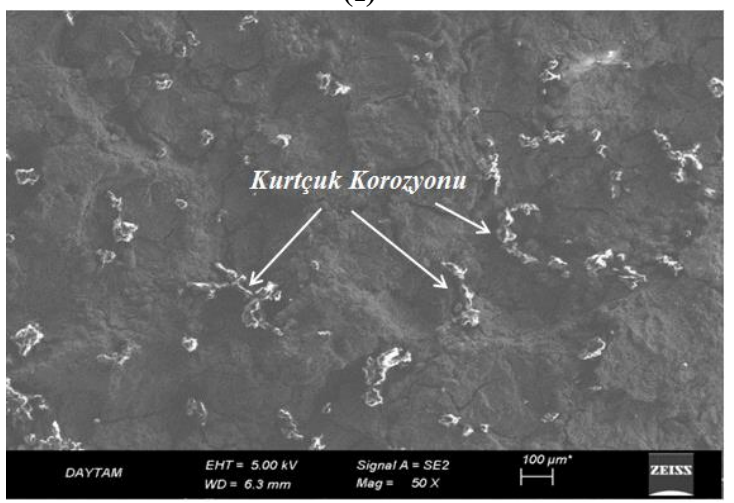

(h)

Şekil 1. Saf Mg ve Mg matrisli kompozitlerin korozyon öncesi/sonrası SEM görüntüleri, (a, b) Saf Mg, (c, d) \% 5, (e, f) \%15, (g, h) \%25 takviye içeren kompozitler; (a, c, e, g) Korozyon öncesi, (b, d, f, h) Korozyon sonrası 


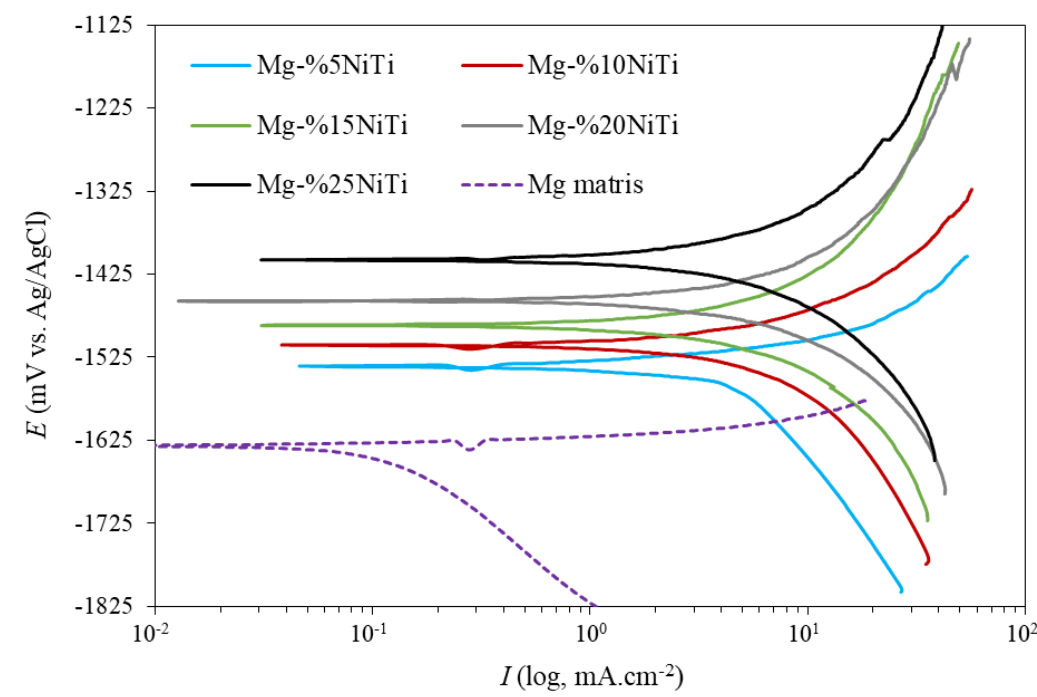

Şekil 2. Saf magnezyum ve magnezyum matrisli kompozitlerin potansiyodinamik polarizasyon eğrileri

Tablo 1. Polarizasyon eğrilerinden elde edilen, saf magnezyum ve magnezyum matrisli kompozitlerin korozyon potansiyeli $\left(E_{\text {corr }}\right)$, korozyon akım yoğunlukları $\left(i_{\text {corr }}\right)$ ve korozyon hizları

\begin{tabular}{lccc}
\hline Numuneler & $\begin{array}{c}\boldsymbol{E}_{\text {corr }} \\
(\mathbf{V})\end{array}$ & $\begin{array}{c}\boldsymbol{I}_{\text {corr }} \\
\left(\boldsymbol{\mu A . c { } ^ { - 2 } )}\right.\end{array}$ & $\begin{array}{c}\text { Korozyon Hozl } \\
(\text { mm/yl })\end{array}$ \\
\hline Saf Magnezyum & -1.630 & 10.7 & 0.245 \\
Mg - \%5TiNi & -1.550 & 210 & 4.57 \\
Mg - \%10TiNi & -1.510 & 211 & 4.69 \\
Mg - \%15TiNi & -1.490 & 213 & 4.99 \\
Mg - \%20TiNi & -1.470 & 236 & 5.05 \\
Mg - \%25TiNi & -1.410 & 282 & 5.59 \\
\hline
\end{tabular}

\section{Sonuç ve öneriler}

Tek eksenli sıcak presleme tekniği ile üretilen magnezyum matrisli kompozitlerde çalış1lan tüm oranlarda TiNi takviye fazının matris tane sınırlarında yer aldığı ve takviye fazının yüksek oranlarda bir biri ile bağlantılı bir ağ yapısı oluşturduğu gözlenmiştir.

Kompozit malzemelerde artan takviye (TiNi) oranı ile birlikte oluşan ağ yapısındaki sürekliliğin arttığı belirlenmiştir.

TiNi ile takviye edilmiş magnezyum matrisli kompozitlerin polarizasyon eğrileri saf magnezyum numune ile kıyaslandığında \% TiNi oranı arttıkça korozyon potansiyeli $\left(E_{\text {corr }}\right)$ ve korozyon akım yoğunluğu $\left(i_{\text {corr }}\right)$ değerlerinin de arttığı dolayısıyla korozyon direncinin azaldığı tespit edilmiştir. Yüzeyde oluşan pasif film tabakasının koruyucu olmaması ve mikroyapıdaki poroziteler nedeniyle yüzeyde çukurlar oluşmuştur. Kompozit malzemelerin tamamında çukurcuk korozyonunun yanı sıra kurtçuklarda gözlenmiştir.

\section{Teșekkür}

Bu çalışmayı maddi olarak destekleyen Türkiye Bilimsel ve Teknolojik Araştırma Kurumu'na ve Van Yüzüncü Yıl Üniversitesi Bilimsel Araştırma Projeleri Birimi Başkanlığı'na teşekkürlerimizi sunarız (Proje No: TÜBITTAK-215M808, BAP-2015-FBE-D275). Ayrıca saf magnezyum partiküllerinin tedarik edildiği, Magnezyum ve Metal Tozları Endüstri ve Ticaret Anonim Şirketine teşekkür ederiz. 


\section{Kaynaklar}

[1] Gaines L., Cuenca R., Stodolsky F., Wu S. 1996. Potential automotive uses of wrought magnesium alloys, In Automotive Technology Development Conference, pp: 24-28, 29-30 April, Detroit, Michigan, USA.

[2] Mordike B.L., Ebert T. 2001. Magnesium: properties-applications-potential. Materials Science and Engineering A, 302 (1): 37-45.

[3] Joost W.J. 2014. Automotive Magnesium: Impacts and Oppurtunities. Magnesium Technology, Edited by Alderman M., Manuel M.V., Hort N., Wiley-TMS, 3-4.

[4] Friedrich H., Schumann S. 2001. Research for a "new age of magnesium" in the automotive industry. Journal of Materials Processing Technology, 117 (3): 276-281.

[5] Kelen F., Aydoğmuş T., Gavgali M. 2015. Otomotiv Uygulamaları için TiNi ile Takviye edilmiş Magnezyum Bazlı Kompozitlerin Geliştirilmesi. Mühendislikte Yeni Teknolojiler Sempozyumu, pp: 45, 22-24 Ekim, Bayburt.

[6] Kelen F., Aydoğmuş T., Gavgali M. 2016. Shape Memory Meterials for Improvement of the high Temperature Strenght of Magnesium and Its Alloys. International Conference on Material Science and Technology in Cappadocia, pp: 538-543, 6-8 Nisan, Nevşehir.

[7] Kelen F., Aydoğmuş T., Gavgali M., Dikici B. 2018. Mg/NiTi Metal Matrisli Kompozitlerin Korozyon Duyarlılıklar. XVth International Corrosion Symposium (KORSEM'18), pp: 19, 26-28 Eylül, Hatay.

[8] Kelen F., Aydoğmuş T., Gavgalı M., Dikici B. 2018. TiNi ile Takviye Edilmiş AZ91D Matrisli Kompozitlerin Korozyon Davranışı, XVth International Corrosion Symposium (KORSEM'18), pp: 20, 26-28 Eylül, Hatay.

[9] Song G., StJohn D.H. 2005. Corrosion of magnesium alloys in commercial engine coolants. Materials and Corrosion, 56 (1): 15-23.

[10] Esmaily M., Svensson J.E., Fajardo S., Birbilis N., Frankel G.S., Virtanen S., Arrabal R., Thomas S., Johansson L.G. 2017. Fundamentals and advances in magnesium alloy corrosion. Progress in Materials Science, 89: 92-193.

[11] Brown R.E. 2006. Magnesium and Its Alloys, Mechanical Engineers' Handbook. Vol: 1, Third Edition, Materials and Mechanical Design, Edited by Kutz, M., New Jersey, 278-286.

[12] Pekguleryuz M.O., Kaya A.A. 2003. Creep resistant magnesium alloys for powertrain applications. Advanced engineering materials, 5 (12): 866-878.

[13] Nguyen Q.B., Gupta M. 2010. Enhancing mechanical response of AZ31B using $\mathrm{Cu}+$ nano- $\mathrm{Al}_{2} \mathrm{O}_{3}$ addition. Materials Science and Engineering A, 527 (6): 1411-1416.

[14] Hassan S.F., Gupta M. 2002. Development of a novel magnesium/nickel composite with improved mechanical properties. Journal of alloys and compounds, 335 (1-2): L10-L15.

[15] Aydogmus T. 2015. Processing of interpenetrating Mg-TiNi composites by spark plasma sintering. Materials Science and Engineering A, 624: 261-270.

[16] Esen Z. 2012. The effect of processing routes on the structure and properties of magnesium-TiNi composites. Materials Science and Engineering A, 558: 632-640.

[17] Hodgson D.E., Wu M.H., Biermann R.J. 1990. Properties and Selection:Nonferrous Alloys and Special-Purpose Materials. ASM Handbook Committee, 2: 897-902.

[18] Kelen F., Aydoğmuş T., Gavgalı M. 2018. TiNi İle Takviye Edilmiş Mg Matrisli Kompozitlerin Sicak Presleme Yöntemi İle Üretilmesi. $1^{\text {st }}$ International Symposium on Ligth Alloys and Composite Materials (ISLAC'18), pp: 288-289, 22-24 Mart, Karabük.

[19] Aydoğmuş T., Kelen F., Gavgalı M. 2018. Sicak Presleme Yöntemi İle Üretilmiş AZ91/TiNi Kompozitlerinin Mikroyapisı. $1^{\text {st }}$ International Symposium on Ligth Alloys and Composite Materials (ISLAC'18), pp: 290-291, 22-24 Mart, Karabük.

[20] Kelen F. 2018. TiNi ile Takviye Edilmiş Mg/AZ91 Matrisli Kompozitlerin Üretimi ve Karakterizasyonu. Doktora Tezi, Atatürk Üniversitesi, Fen Bilimleri Enstitüsü, 197s, Erzurum.

[21] Ghali E., Dietzel W., Kainer K.U. 2004. General and localized corrosion of magnesium alloys: a critical review. Journal of Materials Engineering and Performance, 13 (1): 7-23.

[22] Lindström R., Johansson L.G., Thompson G.E., Skeldon P., Svensson J.E. 2004. Corrosion of magnesium in humid air. Corrosion Science, 46 (5): 1141-1158. 
[23] Kelen F., Gavgali M., Aydogmus T. 2018. Microstructure and mechanical properties of a novel TiNi particulate reinforced AZ91 metal matrix composite. Materials Letters, 233: 12-15.

[24] Hillis J. 2006. Corrosion, Magnesium Technology. Edited by Friedrich H.E., Mordike B.L. Springer-Verlag, Berlin, Germany, 469-498.

[25] Ferrando W.A. 1989. Review of corrosion and corrosion control of magnesium alloys and composites. Journal of Materials Engineering, 11 (4): 299-313.

[26] Dikici B., Esen Z., Duygulu O., Gungor S., 2015. Corrosion of Metallic Biomaterials, Advances in Metallic Biomaterials Tissues Materials and Biological Reactions. Edited by Niinomi M., Narushima T., Nakai M., Springer-Verlag, London, 275-303. 